\title{
Polar Voices: Relaying the Science and Story of Polar Climate Change
}

\section{by Annie Quinney}

$P$

olar Voices is an EDUCATIONAL PODCAST that explores climate change in the Arctic and the Antarctic. The program uses current research to explain observations made by people living and working near the poles, focusing particularly on Arctic Indigenous peoples. Because the podcast format is popular, free to use, available on demand, and can be broadcast on radio stations in rural and remote places, Polar Voices has the potential to reach a large audience and increase knowledge of climate change in a broad demographic of listeners.

\section{HISTORY}

Polar Voices (Fig. 1) is part of the Polar Learning And Responding (PoLAR) Climate Change Education Partnership led by Columbia University. The PoLAR Partnership is funded by the National Science Foundation (NSF) and is intended to advance climate change knowledge and affect behavioral changes in the general public through games. Because games allow learners to actively engage with content, players are more likely to retain information (Barnes et al., 2007). Although Polar Voices is a podcast, it does have advantages over traditional games. First, the format is familiar and easy to use, allowing consumers to access information without learning anything new such as game rules. Second, the content is free and available on demand via the Internet. In the future, the program will also be broadcast on radio stations in rural communities that lack Internet access. Because the podcast format does not exclude potential consumers through lack of access or financial or time constraints (i.e., having to purchase and learn how to play a new game or use a new app), the podcast format is ideal for conveying information about climate change to a large audience.

In keeping with the high entertainment value of many of the other PoLAR products (i.e., board games, card games, and apps), the first season of Polar Voices combined a documentary style with a fictional storyline. The original concept followed fictional characters as they prepared a museum display. In the process, they met with scientists and discussed climate change. The first season of Polar Voices went live on YouTube and thepolarhub.org in 2014. Although the format was novel, initial listeners failed to achieve the learning goals of each episode. During a focus group, participants were asked to listen to an episode of Polar Voices, then

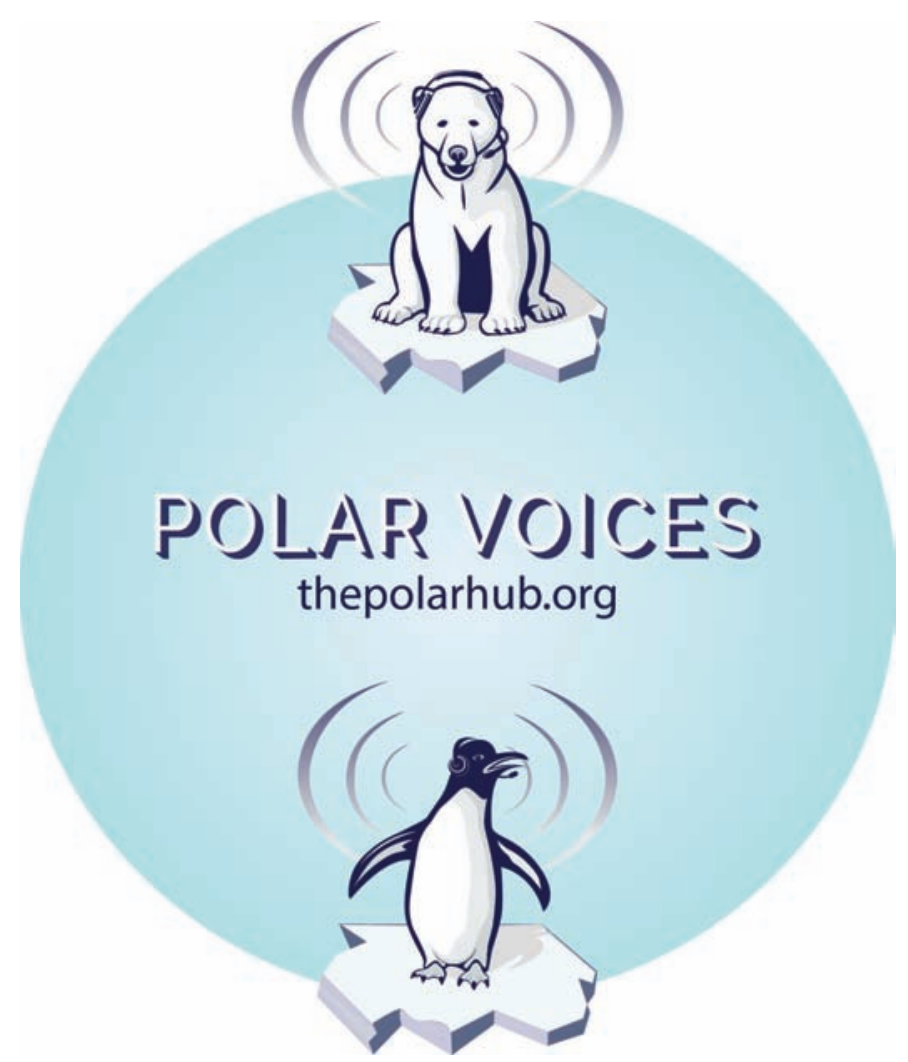

FIG. 1. The Polar Voices logo, representing stories of climate change from the Arctic and the Antarctic.

answer episode-specific questions about climate change. Four out of five participants responded incorrectly to these questions, and correct answers came from prior knowledge of climate change. Participants indicated that they were confused by the mix of documentary and fiction and were so distracted by the complex narrative that they missed any scientific discussion. Clearly, the program was not advancing knowledge of climate change in its listeners.

The format was also problematic because the episodes had to be listened to sequentially; people who listened to them out of order lost the thread of the storyline. Although fine for the online listener, this format was not conducive to radio broadcast except for the dedicated listener.

Once we realized that the educational goals of Polar Voices were not being met, we abandoned the scripted story line and restructured the episodes into standalone pieces of scientific journalism. The new format explores climate 


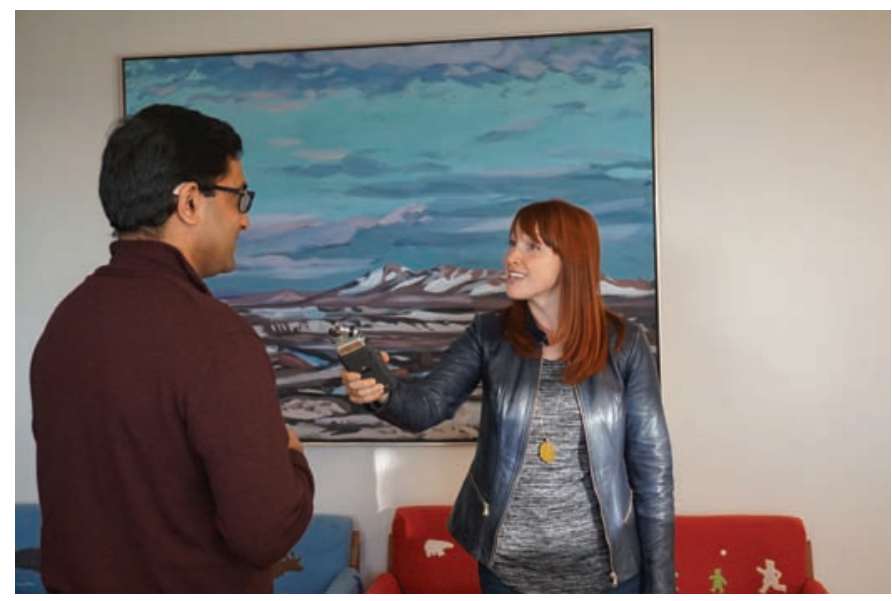

FIG. 2. Project lead Annie Quinney conducting an interview for an episode of Polar Voices.

change from the Indigenous and scientific perspectives, using both in situ observations and scientific data to explore change. The first three episodes of the second season went live in December 2015, and the next three were scheduled for release in February 2016.

\section{LEARNING OBJECTIVES AND GOALS}

The main goal of Polar Voices is to increase knowledge and awareness of climate change in adult listeners from a broad range of socioeconomic and educational backgrounds. For listeners with limited initial knowledge of climate change, we present scientific information in simple and concise language. For listeners with moderate or advanced knowledge of climate change, we relay true stories from Arctic Indigenous communities experiencing and adapting to change and discuss actions people and communities are taking to mitigate climate change locally.

The specific learning topics of each episode vary widely. In our first three episodes, we discuss a) efforts by the Snowchange Cooperative in Finland to incorporate the Indigenous perspective into Arctic policies, b) local observations of changing ice conditions on Alaskan rivers made by Alaska Native Elders, and c) the photo-documentation of Arctic greening, which is occurring as a result of the progressive northward invasion of shrubs. Upcoming episodes will highlight a) increased fire activity in the North, b) food insecurity issues resulting from shifting and disappearing wildlife habitats, and c) the potential release of greenhouse gases stored in thawing permafrost. In the future, we will be examining the impact of climate change in the Antarctic, Greenland, and Russia, and how changes in these remote places will impact people around the world. Each episode features one or more interviews dealing with a specific topic. Although learning objectives vary by topic, each episode is designed to produce one to three key learning outcomes based on information listeners will hear in the featured interview(s) (Fig. 2). The interviewees are experts in their fields, and their comments are vetted by reviewers to ensure accuracy.

\section{EVALUATION}

Demographic data from Google Analytics, iTunes, and participating radio stations will be collected to determine who is listening to Polar Voices. This information will be used to broaden the appeal of future episodes.

Early in 2016, we will be working with the Goodman Research Group in the United States to develop and deliver pre- and post-surveys. Twenty adults from a broad range of cultural, educational, and socioeconomic backgrounds will be recruited to participate. The surveys will assess knowledge gains and listener enjoyment. Participants will be given an honorarium once the surveys are completed.

\section{FUTURE PLANS}

Funding for the PoLAR Partnership under NSF continues until August 2017. Polar Voices is scheduled to produce 21 episodes in the new format during this time, including the three episodes currently available online. Final evaluation of the Polar Voices project will commence in spring 2017.

To hear full episodes of Polar Voices online, go to http:// thepolarhub.org/project/polar-voices. Feel free to leave a comment or suggest episode topics under the "Learn More" tab, or send your feedback directly to the project lead, Annie Quinney, at aequinne@ucalgary.ca. If you have observed or are conducting research on climate change in the Arctic or Antarctic and want to be featured in a future episode of Polar Voices, please contact Annie to arrange an interview.

\section{ACKNOWLEDGEMENTS}

Polar Voices is a collaborative project of the Arctic Institute of North America (AINA) and the University of Alaska Museum of the North (UAMN) and is part of the PoLAR Climate Change Education Partnership. The principal investigator is Dr. Maribeth Murray, AINA Executive Director and Professor in the Department of Archeology and Anthropology at the University of Calgary. The program is produced by Kelsey Gobroski and Roger Topp at UAMN.

\section{REFERENCE}

Barnes, T., Richter, H., Powell, E., Chaffin, A., and Godwin, A. 2007. Game2Learn: Building CS1 learning games for retention. Special Interest Group on Computer Science Education (SIGCSE) Bulletin 39(3):121-125.

Annie Quinney is a postdoctoral fellow at AINA and is the project lead for Polar Voices. aequinne@ucalgary.ca 